\title{
Acquired motility disorders in childhood
}

\author{
PJ Milla MSc MBBS FRCP
}

PJ Milla. Acquired motility disorders in childhood. Can J Gastroenterol 1999;13(Suppl A):76A-84A. Acquired motility disorders in childhood cause a number of gastrointestinal symptoms - principally, recurrent vomiting, abdominal pain and distension, constipation and loose stools. Gastrointestinal motility disorders result from disturbances of the control mechanisms of gut motor activity, which may be produced by organic disease involving enteric nerves and muscle, perturbation of the humoral environment of the nerves and muscle, and altered central nervous system input. In children, both congenital and acquired disease processes may produce these pathogenetic mechanisms, resulting in syndromes that vary in severity from chronic intestinal pseudo-obstruction to the irritable bowel syndrome.

Key Words: Acquired motility disorders, Irritable bowel syndrome, Rumination, Toddler diarrhea

\section{Les troubles de motilité infantiles acquis}

RÉSUMÉ : Les troubles de motilité infantiles acquis provoquent plusieurs symptômes gastro-intestinaux, principalement les vomissements récurrents, les douleurs et la distension abdominales, la constipation et la diarrhée. Les troubles de motilité gastro-intestinale résultent d'anomalies de la régulation des mécanismes de l'activité motrice intestinale, qui peuvent découler de maladies organiques mettant en cause les nerfs et les muscles entériques, la perturbation de l'environnement humoral des nerfs et des muscles et une perturbation de l'influx du système nerveux central. Chez les enfants, les processus pathologiques acquis et congénitaux peuvent engendrer les mécanismes pathologiques responsables de ces syndromes qui varient en intensité, de la pseudo-obstruction intestinale chronique au syndrome du côlon irritable.
A cquired motility disorders in childhood cause a number of gastrointestinal symptoms - principally, recurrent vomiting, abdominal pain and distension, constipation and loose stools. Gastrointestinal motility disorders result from disturbances of the control mechanisms of gut motor activity. Such disturbances may be produced by organic disease involving enteric nerves and muscle, perturbation of the humoral environment of the nerves and muscle, and altered central nervous system input. In childhood, both congenital and acquired disease processes may produce these pathogenetic mechanisms, resulting in syndromes that vary in severity from chronic intestinal pseudo-obstruction to the irritable bowel syndrome (IBS). In childhood, these disease processes also operate on a background of the developmental processes that the child undergoes. For this reason, together with the interaction of the children with their parents and with society, their problems are often considerably different from those of adults. A large body of evidence has accumulated to suggest that these functional symptoms may be caused by disordered gastrointestinal motility in situations where no obvious organic disease can be found, and in this context, the disorders are referred to as functional bowel disorders, of which IBS is one. In the present review, only acquired disorders and functional disorders are considered.

In some patients, all of the symptoms mentioned above occur at one time or another, but in others, one symptom predominates almost to the exclusion of the rest. In adults, functional bowel disorders are a major cause of industrial absenteeism (1) and in children are probably the single most common reason for referral to pediatric gastroenterology clinics. Despite these factors and results from numerous studies, the information regarding the pathogenesis of functional 
COPYRIGHT PULSUS GROU

bowel disorders in children remains fragmentary. The cause of the intestinal dysmotility is almost certainly multifactorial, with an interplay of psychogenic and organic disorders. Disorders of motor activity in individuals with functional bowel disorders have been found throughout the gastrointestinal tract.

\section{MECHANISMS OF DISORDERED MOTILITY}

It is generally accepted that disordered gastrointestinal motility occurs as a consequence of disturbance of the complex control mechanisms of gastrointestinal motor activity. Such disturbances may be produced by organic disease of the control mechanisms themselves. Acquired disease directly affecting the enteric nerves and muscle tends to present with more severe symptoms of dysphagia, vomiting, obstruction or constipation due to conditions such as achelesia, intestinal pseudo-obstruction, or a Hirschsprung's or Hirschsprung's-like condition. The best understood disease processes causing acquired enteric neuromuscular disease are a variety of autoimmune conditions affecting enteric nerve and muscle, and the blocking and binding of pharmacological agents such as guanethidine, morphine and vinca alkaloids to enteric nerves (2). These conditions cause a loss of peristaltic activity of the region of the gut in which they occur, resulting in the failure of the lower esophageal and internal anal sphincter to relax, and loss of cyclical fasting activity. In contrast, perturbation of the humoral environment in which the nerves and muscles of the gastrointestinal tract operate, and of central nervous system input result in less severe and often paroxysmal symptoms. This may occur by a variety of disease processes, such as food-induced hypersensitivity and other immune responses, and inflammatory bowel disease by virtue of the interaction that occurs between gut-associated lymphoid tissue and the enteric neuromusculature. Conditions such as chronic renal failure and endocrine disease, particularly thyroid disorder, by their effect on polypeptides and other hormones, affect contractile activity of the enteric musculature. In functional bowel disorders, there is no evidence of organic disease directly affecting enteric nerve and muscle, but an accumulating body of evidence implicates both an altered humoral environment similar to those of the acquired conditions discussed above and central nervous system input to the gut.

\section{THE HUMORAL ENVIRONMENT IN FUNCTIONAL BOWEL DISORDERS}

A variety of disease processes such as food allergic responses and other immune responses may alter the humoral environment and produce disordered motor activity that may be viewed as causing IBS-like symptoms. Experimental studies of small intestinal motility during acute immediate hypersensitivity reactions in animals have shown the presence of giant migrating complexes and clustered phasic activity $(3,4)$, both of which result in shortened transit. Such disordered motility may result in IBS-like symptoms, especially in patients with toddler diarrhea. No comparable studies have been performed in children with similar immune responses.
INC, DO NOT COPY

Effects of laboratory stressors on gastrointestinal motor activity

\begin{tabular}{lll}
$\begin{array}{l}\text { Region of the } \\
\text { gastrointestinal tract }\end{array}$ & \multicolumn{1}{c}{ Stressor } & \multicolumn{1}{c}{ Effect } \\
\hline $\begin{array}{l}\text { Esophagus } \\
\text { Stomach }\end{array}$ & $\begin{array}{l}\text { Noise } \\
\text { Cold stress }\end{array}$ & $\begin{array}{c}\text { Increased peristalsis } \\
\text { Inhibited antral motility } \\
\text { and gastric } \\
\text { emptying* }\end{array}$ \\
Small intestine & $\begin{array}{c}\text { Delayed auditory } \\
\text { feedback, arcade } \\
\text { games and driving } \\
\text { in traffic }\end{array}$ & $\begin{array}{c}\text { Suppressed fasting } \\
\text { activity }^{\dagger}\end{array}$ \\
Colon & Cold stress & Increased motility
\end{tabular}

*From reference 50; ${ }^{\dagger}$ From reference 51; ${ }^{*}$ From reference 52

Results of preliminary studies of T lymphocyte-mediated responses in the small intestinal mucosa of both adults and children suggest that similar clustered, phasic activity is present in some patients. Recently, preliminary studies of vomiting due to gastroesophageal reflux have shown that immunomodulation of the enteric neuromusculature takes place in patients with cow's milk allergy (5). In a small number of patients with documented atopy and immunoglobulin A deficiency, studies of gastric myoelectrical activity showed a highly significant increase in postprandial electrical control activity compared with fasting electrical control activity (fasting: control $2.36 \pm 0.05$ counts $/ \mathrm{min}$, allergic $2.6 \pm 0.07$ counts/min; postprandial activity: control $2.48 \pm 0.03$ counts/min, allergic $2.83 \pm 0.03$ counts $/ \mathrm{min})$. The postprandial to preprandial power ratio was significantly diminished in the allergic group (control 15.6 \pm 1.1 , allergic 2.6 \pm 0.06 ). Challenge of the food-allergic children with cow's milk resulted in a number of abnormalities of gastric electrical control activity, with marked dysrhythmia and activation of the emetic reflex. Thus, these results suggest that immune modulation of the enteric neuromusculature results in the disturbance of foregut motility and, therefore, may exacerbate gastroesophageal reflux. Thus, a variety of immune responses in the gut may result in disordered motility, which may cause IBS-like symptoms.

\section{THE CENTRAL NERVOUS SYSTEM, STRESS AND IBS}

Central nervous system activity modulates intestinal motor activity, and the role of stress and emotion in producing disordered gastrointestinal motor activity is supported by experimental and anecdotal studies. The induction of a gastrointestinal motor response by fear or anxiety is well known. Results of experimental studies, some of which are summarized in Table 1, show that a wide variety of stressors are able to induce disordered gastrointestinal motor activity. As a consequence, stressful events, which in childhood may be family tension, separation, major life changes such as that of school or house (6), difficulty in peer relationships, or loss of important friends or relatives, may induce changes in gastrointestinal motor activity that clinically present as IBS. 


\section{COPYRIGHT PULSUS GROUP INC, D DO NOT COPY}

Such stresses may be acute or chronic, overt or covert, or minor or major. Too often, significant stresses are overlooked simply because they are not major or obvious traumatic events but are subtle, low key, persistent and sometimes unclear to the outsider. Some studies have suggested that different emotions may have different effects. For example, fear and depression have been found to be associated with inhibition of gastric acid secretion and delayed gastric emptying, while resentment, anger and aggression have been found to enhance motor activity and secretion (7). The study of the effects of neuropeptides in the central nervous system on intestinal motor activity, demonstrating changes associated with particular peptides, lends credence to the notion that centrally determined events of different types may result in different changes in motor response in the intestine (8).

While many experimental studies have shown that normal subjects alter their gastrointestinal motility response to psychological stress, it seems that patients suffering from IBS have a motility response that is qualitatively different from that in normal individuals, and there are now many pieces of indirect evidence to support this theory. Richter et al (9) showed that patients with noncardiac chest pain had a lower threshold for reporting pain when a balloon was inflated in the esophagus. Similarly, Moriarty and Dawson (10) showed that IBS subjects reported pain at lower levels of distension in both the small and large intestines on balloon dilation. Although the available data provide persuasive evidence that psychological stress may exacerbate gastrointestinal motility disorders, the high frequency with which psychological stress precipitates altered bowel habits in normal subjects must be taken into account. For example, Drossman et al (11) found that $68 \%$ of a large population sample without symptoms of IBS reported that psychological stressors caused constipation or diarrhea; $47 \%$ reported that psychological stressors caused abdominal pain. On the other hand, IBS patients were significantly more likely to report stress-related changes in bowel patterns (85\%) and abdominal pain $(69 \%)$, but the rate of such reports among the controls suggested that this is not a distinct characteristic of IBS patients.

In summary, studies of the effects of laboratory stressors and of naturally occurring stress generally agree that stress alters gastrointestinal motility. However, these stress-mediated changes occur in healthy subjects as well as in IBS patients. There is some indirect evidence to suggest that patients with IBS have a greater reactivity to stress than subjects, but the overlap is substantial. The physiological mechanisms that mediate such effects are unclear. Studies of gastrointestinal peptides, both centrally and peripherally, suggest that they are important in pathogenetic mechanisms.

\section{FUNCTIONAL BOWEL DISORDERS}

In childhood, patients with functional bowel disorders fall into four main groups, those whose predominant symptom is vomiting, those who have abdominal pain, those whose main complaint is of loose, frequent stools and those who present with constipation. These four groups are discussed with regard to the etiology and pathophysiology of their disease.

\section{Recurrent vomiting}

Three functionally based syndromes involving recurrent vomiting are recognized, including infant regurgitation, rumination and cyclical vomiting.

Infant regurgitation: Infant regurgitation, possetting or spitting up is recognized worldwide in infants who are milk-fed in early life, epitomized by Shakespeare's description of the mewling, puking infant in his seven ages of man speech. The history of the condition is the effortless return of gastric contents out of the mouth two or more times per day in the absence of nausea and abdominal pain, retching, hematemesis, aspiration, apnea, failure to thrive and abnormal posturing. The first three symptoms are of activation of the emetic reflex, and the latter five are of gastroesophageal reflux disease. The condition occurs more often in formula-fed infants and is less common in infants who are breastfed. The condition is almost certainly a variant of development of the neuromusculature of the lower esophagus and stomach, and is not associated with anatomical abnormalities such as hiatus hernia, gastric outlet obstruction or malrotation. The episodes of reflux are due to one or both of two mechanisms - transient lower esophageal sphincter relaxation and abdominal contraction during swallowing when the lower esophageal sphincter has opened (12).

The condition almost invariably responds to simple measures such as changing the infants position, ie, lying him or her in the left lateral position, or thickening the gastric contents by feeding with a variety of substances such as carob flour. It is very unusual to require gastrointestinal prokinetic agents or acid suppression. The natural history of the condition is complete disappearance as the infant develops, usually by the age of 12 months, by which time there have been a number of major changes in the child's growth and environment. The esophagus grows longer so that the intra-abdominal portion is greater, there almost certainly is maturation of enteric innervation, the child no longer spends most of the waking day in the prone position but at least crawls and almost certainly walks, and the diet changes from a largely liquid diet to one in which solid food predominates.

Rumination: Rumination consists of the regurgitation of ingested food and subsequent remastication with reswallowing or spitting out. In childhood, the condition is expressed clinically in three settings (13). The mechanism for all forms of rumination appears to be voluntary abdominal contraction when the lower esophageal sphincter is open, which is usually induced by swallowing. Others have regarded this as a voluntary form of belch reflex (14).

Infants: In infants, rumination usually occurs after the age of three months and is often a major cause of failure to thrive. It is thought to a be self-stimulating behaviour caused by impaired caretaker-child relationships in response to absent nurturing. It generally occurs only when the infant is alone, 


\section{COPYRIGHT PULSUS GROUP INC, D DO NOT COPY}

but the subsequent suppression of appetite leads to poor feeding and, in severe cases, may lead to malnutrition and severe gastroesophageal reflux disease (15). Treatment consists of psychosocial intervention to alter the disturbed nurturing environment and conventional treatment of the gastroesophageal reflux disease, if present. In the short term, nasogastric feeding ensures an adequate caloric intake but is usually unnecessary when a surrogate mother is provided.

Neurodevelopmentally retarded individuals: Pediatricians and pediatric neurologists commonly observe neurodevelopmentally delayed children who ruminate continuously. In this circumstance, the behaviour is almost certainly selfstimulating but is in response to the abnormal interaction with the environment. Such children commonly have gastroesophageal reflux disease. Several studies have documented that gastroesophageal reflux occurs in two-thirds to three-quarters of neurodevelopmentally retarded children. In this context, treatment of the gastroesophageal reflux frequently controls the rumination, but the self-stimulating behaviour pattern changes so that another behavioural disturbance may take its place (15).

Older children: Rumination certainly occurs in older children and appears to have very many similarities to that seen in adults. The individual frequently remasticates regurgitated material shortly after feeding, which appears to be a pleasurable activity. The regurgitation and remastication, followed by reswallowing, stop as the gastric contents become acidic after a meal and the regurgitated material becomes bitter. Treatment protocols are the same as those for adult individuals.

Cyclical vomiting syndrome: Cyclical vomiting consists of repeated episodes of activation of the emetic reflex. Clinically, it consists of recurrent stereotyped episodes of intense nausea and vomiting lasting for hours or days separated by symptom-free intervals. In individual patients, the features of the episodes, which typically begin at the same time of day, most commonly during the night or in the morning, are relatively consistent. The duration of most episodes tends to be the same in each patient over months or years. Once vomiting begins, it reaches a typical intensity of 20 or more times per hour during the first hours of an episode. These episodes are so intense that they lead to dehydration. Thereafter, the frequency of vomiting tends to diminish, although nausea continues to the end of the episode. Provided that the patient has not incurred major deficits of fluids or electrolytes, the episodes usually end as rapidly as they begin and are marked by a prompt recovery (16).

About $80 \%$ of patients are able to identify specific conditions that precipitate some or most of their episodes. The most common triggers are heightened emotional states, infections, allergy or physical exhaustion.

The course of the illness is unpredictable and may involve several or several hundred episodes that may recur during the course of a few months or a few decades. A number of complications in severe episodes of cyclical vomiting can be anticipated. These include fluid and electrolyte deficits, peptic esophagitis, Mallory-Weiss tears and occasionally fluid retention due to inappropriate antidiuretic hormone secretion.

A number of underlying conditions may predispose patients to cyclical vomiting, including intracranial spaceoccupying lesions, unsuspected obstructive uropathy, inborn errors of metabolism, especially urea cycle defects, and food allergies. About one-third of patients have clinically significant psychiatric conditions such as anxiety disorder or depression. Panic attacks may trigger episodes of cyclical vomiting. Migraine increases the susceptibility to motion sickness, and other functional bowel disorders are more prevalent in patients with cyclical vomiting and in their families (16).

No standard management has yet been developed for cyclical vomiting, but a number of regimens appear to be logical choices, such as interruption of the emetic reflex with 5-hydroxytryptamine 3 antagonists such as ondansetron and granisetron, and the use of benzodiazepines such as lorazepam. An $\mathrm{H}_{2}$ receptor antagonist or proton pump inhibitor may protect the esophageal mucosa during an episode. Any underlying infective processes should also be treated. A number of other agents, including cyproheptadene, amitriptyline, phenobarbitone and propranolol, have been successfully used in such episodes.

\section{Recurrent abdominal pain}

Apley (17) found that approximately $10 \%$ of school children suffered from recurrent episodes of self-limiting abdominal pain that lasted for longer than three months, interfered with their activities and for which no cause was found. Children with recurrent abdominal pain tend to exhibit one of three clinical presentations - isolated paroxysmal abdominal pain where the pain is usually colicky and periumbilical, abdominal pain associated with symptoms of reflux or dyspepsia, and abdominal pain associated with altered bowel habits. Symptoms of dyspepsia and reflux include pain associated with eating, epigastric or retrosternal pain, vomiting, excessive belching, excessive hiccups, early satiety and bloating, and nausea. Altered bowel habits include diarrhea, constipation and a sense of incomplete evacuation with defecation. Most commonly, the peak incidence occurs around five years of age in both sexes, with a further peak at puberty in girls. Complaints of pain are significantly more common in the families of affected children and seem to be most frequent in high-strung and anxious children. In Apley's study (17) psychogenic factors were more common in children with recurrent abdominal pain than in control children, and symptoms were relieved more rapidly in those treated with informal psychotherapy. However, careful study of the data shows that approximately $40 \%$ of the children were unresponsive to psychotherapy.

That such a high proportion of patients were unresponsive to psychotherapy suggests that obscure organic disease may be the cause of the symptoms. Claims have been made that food intolerance, including both food allergy and lactose intolerence, play a role in this syndrome (18). Some children respond to elimination diets, especially elimination 


\section{COPYRIGHT PULSUS GROUP INC, D DO NOT COPY}

of the more common allergens - cow's milk, eggs and wheat. A strong personal and/or family history of atopic disease and gastrointestinal disturbance, together with a response to an elimination diet, suggests that allergy plays a role in some patients. There is also evidence that food allergy accounts for many cases of migraine in a proportion of patients in whom recurrent abdominal pain is also a feature (19). Earlier suggestions by McMichael et al (20) that lactose intolerance explains many cases has not been proved in practice. Long term studies have suggested that over half of the children who present with recurrent abdominal pain have symptoms that persist into adult life (21) and that in about a third of these cases, IBS is diagnosed (22). In addition to abdominal pain, some children experience intermittent fluctuating episodes of diarrhea and constipation, reminiscent of those experienced by adults with IBS (23), together with nonspecific symptoms such as bloating, nausea and abdominal tenderness.

Pathophysiology: The pathophysiological mechanisms of recurrent abdominal pain are not known, but a variety have been postulated. Attacks may result from the transient somatic correlates of anxiety, depression or anger mediated by the autonomic nervous system, or simple physiological responses. In some children, it appears that the pain that is described is simply the phasic contractions of normal phase III activity of fasting small intestinal motility known as 'hunger pains'. However, in other children with recurrent abdominal pain, increased small intestinal pressure (24) and hyperactive colonic motor responses to cholinergic agonists have been found that are very similar to those seen in adults with IBS (25). Studies of intestinal motor activity in experimental animals in whom immediate hypersensitivity responses have been induced have shown the presence of giant migrating complexes that may also be responsible for abdominal pain in children with IBS (3).

\section{Toddler diarrhea}

Although recurrent abdominal pain is a common problem in general pediatric practice, it is the child with loose, frequent, foul smelling stools who is thriving who most commonly presents to the pediatric gastroenterologist. This symptom complex is known as 'toddler diarrhea', 'chronic nonspecific diarrhea' and 'IBS of childhood'. The condition is most common in children between the ages of one year and five years, most frequently in boys who are typically described as being overactive, a handful, destructive or difficult to cope with. The diarrhea is intermittent and characterized by the precipitous passage of loose stools containing undigested food particles such as peas and carrots. Such stools are only passed during waking hours and are often exacerbated by stress. Despite the abnormal stools, failure to thrive is not a feature of this syndrome. The condition is self-limiting, but a follow-up study (26) found a high incidence of constipation. In the same study, there was a marked familial tendency with recurrent functional bowel disorder in at least one parent of $67 \%$ of patients. In children with unaffected parents, 55\% had a sibling with a similar disorder. Thus, toddler diarrhea or chronic nonspecific diarrhea is part of a spectrum of functional bowel disorder that is present just as frequently in childhood as in adulthood.

Pathophysiology: A variety of mechanisms have been implicated in toddler diarrhea, including changes in intestinal transport and brush border enzymes, prostaglandin synthesis, food intolerance and intestinal motor activity. Despite investigations of these mechanisms, the nature of this common, apparently self-limiting condition is not entirely clear, although we present a hypothesis.

Intestinal transport: Diarrhea is not associated with malabsorption in either adults or in children in the fasting state. There is no evidence of abnormal secretion of water and electrolytes in the small intestine (27), nor of glucose absorption in the proximal jejunum of children with toddler diarrhea (28).

Mucosal enzymes: Although the small intestinal mucosa is morphologically normal, Tripp et al (29) found a significant increase in the specific activities of sodium/potassium ATPase and basal adenylase cyclase in jejunal biopsies of children with toddler diarrhea compared with those of children with postenteritis syndrome. In the active phase of postenteritis syndrome, adenylase cyclase activity was normal and sodium/potassium ATPase activity was reduced. During the recovery phase of postenteritis syndrome, the activities of both enzymes were increased in a similar proportion to those found in patients with toddler diarrhea. These findings add some credence to the clinical impression that toddler diarrhea may follow an acute enteric infection. Tripp et al (29) suggested that the increase in specific enzyme activity was a response of normal villus cells to crypt cell secretion and that this secretion may be mediated via prostaglandins. Prostaglandins: Using a radioimmunoassay for prostaglan$\operatorname{din} \mathrm{E}_{2}$ and prostaglandin $\mathrm{F}$ in 30 patients with toddler diarrhea and 26 healthy controls, Dodge et al (30) showed that prostaglandin $\mathrm{F}$ was raised in 17 patients and prostaglandin $\mathrm{E}_{2}$ in four patients. A proportion of patients had a good clinical response to acetylsalicylic acid (a prostaglandin synthetase inhibitor) or loperamide (an opiate analogue). Although sequential data were not given in this study, acetylsalicylic acid therapy resulted in a decrease in plasma levels of prostaglandins, but loperamide had little effect. These observations may have some implications with respect to the pathogenesis of toddler diarrhea and its treatment. For example, there is excellent evidence that prostaglandins induce secretion in the small intestine (31) and that loperamide can partially block this effect (32). However, studies both in children and in adults suggest that the upper small intestine is not normally in a secretory state; thus, if excessive secretion is involved, it may take place in either the lower small intestine or the colon.

Food intolerance: A study of adults with IBS suggested that a proportion of patients have unsuspected food allergy and that this may play a role in the pathogenesis of the condition (18). It is certainly the case that some children respond to elimination diets, especially with the more common allergens, such as cow's milk, egg and wheat protein. However, these pa- 


\section{COPYRIGHT PULSUS GROUP INC, DO NOT COPY}

tients can nearly always be differentiated by their personal or close family history of atopy, peripheral blood, high serum immunoglobulin E levels and positive radioallergen absorbent tests or skin prick tests, and ultimately by the response of their symptoms to the elimination of, followed by challenge with, the suspected allergens. Savilahti and Simell (33), in a survey of children with chronic nonspecific diarrhea, showed that a third of such patients had evidence of food allergy and all were atopic. Abnormal results of breath hydrogen tests have suggested that lactose maldigestion and malabsorption are common in IBS patients; however, few patients have clear cut lactose intolerance with the production of watery stools containing lactose in response to a lactose load.

Intestinal motor activity: While abnormal results of breath hydrogen tests may provide evidence of lactose malabsorption they may also provide a measure of small intestinal transit. Thus, an abnormal result may result from the rapid delivery of a large quantity of lactose into the colon because of shortened small intestinal transit, providing reduced contact time in the proximal jejunum. It is of interest that Corbett et al (34) demonstrated decreased small intestinal transit times in adults with IBS, which were increased by treatment with loperamide. Thus, the previously reported beneficial effects of loperamide may be related to an effect on small intestinal motility. It has been known for many years that whole bowel transit time is decreased in children with IBS. Davidson and Waserman (26) showed that starch intolerance, characterized by the presence of starch granules in the stool, was a manifestation of reduced whole gut transit. The popular term 'peas and carrots diarrhea' may also be similarly explained. In studies of small intestinal absorption in toddler diarrhea, it was repeatedly demonstrated that, in patients with toddler diarrhea, transmural potential difference wave forms of large amplitude between 8 and $13 \mathrm{mV}$ occurred during perfusion with glucose, whereas in controls, these waves appeared to be completely suppressed by glucose. Read et al $(27,35)$ reported the presence of these large amplitude wave forms in recordings of small intestinal transmural potential difference and showed them to be associated with phase III activity of the migrating motor complex. The recognition of the propulsive character of phase III activity in humans (36) and the change to continuous segmenting activity without phase III activity in the postprandial state prompted studies of small intestinal motility in children with IBS (37). No differences in fasting activity were found, but initiation of postprandial activity and disruption of the migrating motor complex with interduodenal dextrose was clearly defective in patients with IBS. Further studies have demonstrated that, in patients in whom dextrose did not disrupt the motor complex, abnormalities in postprandial activity were induced by perfusion of the duodenum with soya milk (38). Postprandial activity was weaker and shorter lived, and, in a third of patients, phase III activity occurred postprandially. Similar changes with failure of the migrating motor complex to be disrupted by food have been documented both in experimental animals subjected to vagotomy (39) and in adults who develop postvagotomy diarrhea (40).
Previously isolated findings and the results of the above studies of small intestinal motor activity in toddler diarrhea can be brought together to form a coherent hypothesis. Failure of fasting interdigestive activity to be disrupted with food and a shortened period of weaker postprandial activity may result in propulsive phasic activity postprandially, leading to the rapid transit of small intestinal contents through the small intestine to the colon. The small intestinal effluent dumped into the colon under these circumstances may contain partially digested food and excess bile salts. Further degradation by colonic bacteria may yield secretogogues such as unconjugated bile salts and hydroxy fatty acids, which may adversely affect colonic absorption of water and electrolytes. Similarly, carbohydrates may be dumped into the colon, giving the illusion of lactose intolerance. The bacterial degradation products of all of these substances may also be responsible for increased prostaglandin production, which may play a role in the production of some of the patients' symptoms. Two studies provide some evidence to support this hypothesis. Jonas and Diver-Haber (41) compared stool output and constipation in children with chronic nonspecific diarrhea with those in children with malabsorption due to cystic fibrosis or bacterial overgrowth of the small intestine, and those in controls. They found that, in the extractable water phase, sodium and bile acids were increased in the stools of children with chronic nonspecific diarrhea. These findings may reflect an effect of bile acids on the colonic handling of water and electrolytes. Jones et al (18) showed that in adult patients with IBS, prostaglandin concentration in rectal mucosa was increased when the patients were exposed to foods that precipitated their symptoms.

There is thus a body of evidence suggesting that, in children with the diarrheal variant of IBS, fasting activity in the small intestine is not suppressed by the motor response to food, which results in shortened small bowel transit time. The cause of the inadequate postprandial response is not clear, although abnormal secretion of postprandial polypeptide hormones or numbers or function of polypeptide hormone receptors are clearly areas that require investigation.

\section{Constipation}

Constipation is the infrequent passage of stools that may be small, hard and pellet-like or firm and very large. Leakage of liquid feces around compacted stools in a capacious rectum, causing soiling and secondary anal incontinence, may be associated with these symptoms. Constipation should be clearly distinguished from encopresis, which is the involuntary passage of a normal stool in an inappropriate way or place; this will not be considered further here. The frequency of the passage of stools varies with age; Weaver (42) demonstrated that the average baby passes $4 \pm 1.8$ stools per day during the first week of life, and by the age of one year, this figure falls to approximately 1.6 stools per day and then declines to one stool per day by the age of five years. Most children with idiopathic constipation present around the age of four years 
TABLE 2 COPYRIGHT PULSUS GROUP

\section{Primary diseases of the enteric neuromusculature causing constipation}

Neuronal disease

Neurocristopathies

Hirschsprung's disease

Intestinal ganglioneuromatosis

Piebaldism

Intestinal neuronal dysplasia

Congenital hypoganglionosis

Enteric ganglionitis

Glial cell hyperplasia

Muscle disease

Hollow visceral myopathy

Defective muscle coat morphogenesis

Megacystitis - microcolon-hypoperistalsis syndrome

Absent alpha actin

Muscular dystrophy

Enteric myositis

with a history of approximately six to 24 months. Some are said, by their parents, to have always been constipated, and others have never achieved bowel control. On closer questioning, however, it is uncommon for such infants to clearly have had disturbed defecation since birth, and it is of note that in only $5 \%$ to $6 \%$ of patients subsequently proven to have Hirschsprung's disease or pseudo-Hirschsprung's disease is constipation the only presenting symptom.

In patients with severe constipation that presents in an atypical fashion, such as the sudden onset of constipation in later childhood, evidence should be sought for acquired disease of the enteric neuromusculature. Potentially treatable disease processes include autoimmune disorders affecting the enteric nerves and muscle. The author has recently studied several patients with enteric ganglia associated with a circulating autoantibody directed against enteric neurons similar to those seen in patients with pseudo-obstruction and a paraneoplastic syndrome (43). In another individual with severe constipation and obstruction in the setting of a pyrexia of unknown origin, a very high titre of smooth muscle antibodies and enteric myositis were found. Both enteric ganglionitis and enteric myositis respond to treatment with agents such as prednisolone and cyclosporine.

While patients with chronic nonspecific diarrhea and abdominal pain may be intermittently troubled with constipation, the majority who present with constipation do not experience diarrhea and do not have persistent abdominal pain. Their symptoms are solely constipation or soiling secondary to overflow incontinence. Those who present from birth, that is they fail to pass meconium in the first $24 \mathrm{~h}$ of life, or those who experience persistent symptoms of episodic diarrhea and abdominal pain, require further investigation to exclude neuromuscular disease of the rectum and colon. Rectal biopsy from clearly defined levels using both conventional histology and histochemistry is the definitive investigation for Hirschprung's disease and its variants (44), but anorectal manometry may also be useful. In patients who
INC, : DO NOT COPY

have a history suggestive of Hirschprung's disease, or who have a distended bladder, hydroureter, hydronephrosis or a bladder that fails to empty completely, full thickness biopsy to exclude less common disorders of smooth muscle or enteric nerves is required. Cystic fibrosis should be excluded in those who did not pass meconium in the first $24 \mathrm{~h}$ of life or where there is developmental and growth delay, or hypothyrodism.

Pathophysiology: Children with constipation fall into two groups - the majority, for whom no cause can be found, who may later develop idiopathic megacolon and for whom there is no demonstrable functional abnormality, and the minority, who may have potentially serious pathology (Table 2).

In those with functional constipation, the problem may stem from a number of factors - a bout of constipation associated with loss of appetite due to an acute infection, moving to a new house or a holiday; pain from an anal fissure; or difficult toilet training, either due to unpleasant toilet facilities, eg, inadequate provision at school, or due to a persistent negative developmental phase experienced by some toddlers.

Functional studies have focused mainly on the motility of the rectum and anal sphincters following recognition of the altered anal sphincteric reflexes in Hirschprung's disease (45). In the very large majority of patients with functional constipation and an idiopathic megacolon, unlike those with Hirschprung's disease, the internal sphincter relaxes with rectal distension. In a study of anorectal physiology in 106 children with long standing constipation, Clayden and Lawson (46) found 10 to have an ultrashort segment Hirschprung's disease, ie, failure of the internal sphincter to relax, with distension of the rectum but no ganglia just above the anal verge; 10 others had similar physiological abnormalities but with normal ganglia and nerves found on biopsy. In the remaining 86 cases, the physiological findings were different from those of controls in that a high rectal distension pressure was required to induce relaxation of the internal sphincter and the internal sphincter showed high amplitude rhythmic fluctuations of pressure. It was suggested that failure of the lower portion of the internal sphincter to relax caused functional obstruction and compensatory hypertrophy of the upper portion of the internal sphincter. About $40 \%$ of these patients had a dramatic response to a single anal dilation and a further $9 \%$ responded to repeat dilation and sphincterotomy.

Clearly, whether the physiological abnormalities were primary or secondary remains to be determined. Davidson et al (47) showed a failure of some patients to produce an increase in colonic motility in response to acetylcholine. Subsequent failure to improve dramatically following an anal pull-through operation suggested that some form of neuromuscular disease was present. A dynamic test of colonic motor activity may be useful in children with chronic constipation to distinguish the more resistant cases of abnormal colonic function.

In atypical patients with severe disease, consideration should be given to screening investigations for enteric neuromuscular disease. In the author's practice, the screen- 
COPYRIGHT PULSUS GROUP

ing investigations performed include radio-opaque pellet
transit studies and electrophysiology. In some patients, antroduodenal manometry may be helpful in suggesting the presence of underlying disease when an atypical myopathic neuropathic pattern is found.

\section{ETIOLOGICAL FACTORS FOR IBS}

An accumulating body of evidence suggests that feeding and the environment of infants around birth may subsequently have a long lasting effect on the function of their gastrointestinal tract. Several lines of evidence suggest that autonomic reactivity patterns are established early in infancy, but it is not clear what effects that organic, mechanical or emotional factors have on the developing motor control systems of the infant's gut. It is clear that several stages of development in intestinal motor activity in humans occur prenatally and in early infancy $(48,49)$. Control and effector systems are involved in such developmental processes, and it is possible that functional disorders of the gastrointestinal tract may start insidiously and act in conjuction with the setup of autonomic control patterns in the infant's gut. Subsequently, some of these minor deviations in function may be more prone to exaggeration and develop into lasting symptomatic disorders such as IBS as a result of the influence of environmental circumstances or events.

\section{REFERENCES}

1. Almy TP. Digestive disease as a national problem. Gastroenterology 1967;53:821-33.

2. Milla PJ. Intestinal pseudo-obstruction in children. In: Kamm M, Lennard-Jones J, eds. Constipation. Petersfield: Wrighton Biomedical Publishing Ltd, 1994:251-8.

3. Scott RB, Diamant SG, Gall DG. The motility effects of $\operatorname{IgE}$ medicated intestinal anaphylaxis in the rat. Dig Dis Sci 1987;32:927.

4. Vermillion D, Scicchitano R, Ernst P. Immunomodulation of gut motility: involvement of connective tissue in mast cells. Dig Dis Sci 1987:32:931.

5. Boulton RS, St Louis D, Lindley KJ, Milla PJ. Immuno-modulation of the enteric neuromusculature in cow's milk allergy. J Pediatr Gastronterol Nutr 1995;20:447.

6. Berger MG. Somatic pain and school avoidance. Clin Pediatr (Phila) 1974;13:815-8.

7. Cann P, Read N, Brown C. Psychological stress and the passage of a standard meal in man. Gut 1983;24:236-40.

8. Ewart WR, Wingate DL. Central representation and opioid modulation of gastric mechanoreception activity in the rat. Am J Physiol 1983;244:G27-32.

9. Richter JE, Barish CF, Castell DO. Abnormal sensory perception in patients with esophageal chest pain. Gastroenterology 1986;91:845-52.

10. Moriarty KJ, Dawson AM. Functional abdominal pain. Further evidence that whole gut is affected. Br Med J 1982;ii:1670-2.

11. Drossman DA, Sandler RS, McKee D, Lovitz AJ. Bowel patterns among subjects not seeking health care. Gastroenterology 1982;83:529-34.

12. Mahony MJ, Migliavacca M, Spitz L, Milla PJ. Motor disorders of the oesophagus in gastro-oesophageal reflux. Arch Dis Child 1988;63:1333-8.

13. Mayes SD, Humphrey FJ, Handford HA, Mitchell JF. Rumination disorders: differential diagnosis. J Am Acad Child Adolescent Psychiatry 1988;27:300-2.

14. Amamath RP, Abell TL, Malagelada JR. The rumination syndrome in adults: a characteristic manometric pattern. Ann Intern Med 1986;105:513-8.

15. Herbst J, Friedland GW, Zboralske FF. Hiatal hernia and rumination in infants and children. J Pediatr 1971;78:261-5.
16. Fleisher $\mathrm{D}$ Matar $\mathrm{M}$. $\mathrm{CO}$ Gastroenterol Nutr 1993;17:361-9.

17. Apley J. The Child with Abdominal Pains. Oxford: Blackwell Scientific Publications, 1959.

18. Jones VA, McLaughlan P, Shorthouse M, Workman E, Hunter JO. Food intolerance: a major factor in the pathogenesis of irritable bowel syndrome. Lancet 1982;ii:1115-7.

19. Egger J, Carter CM, Wilson J, Turner MW, Soothill JF. Is migraine food allergy? A double-blind controlled trial of oligoantigenic diet treatment. Lancet 1983;ii:865-9.

20. McMichael HB, Webb J, Dawson AM. Lactose deficiency in adults: Cause of functional diarrhoea. Lancet 1965;i:717-20.

21. Apley J, Hale B. Children with recurrent pain. How do they grow up? Br Med J 1973;3:7-9.

22. Christensen MF, Mortensen O. Long-term prognosis in children with recurrent abdominal pain. Arch Dis Child 1975;50:110-4.

23. Drossman DA, Powell DW, Sessions JT Jr. The irritable bowel syndrome. Gastroenterology 1977;73:811-22.

24. Horowitz L, Farrar JT. Intraluminal malintestinal pressures in normal patients and in patients with functional gastrointestinal disorders. Gastroenterology 1962;42:455-64.

25. Kopel FB, Kim JC, Barbero GJ. Comparison of recto-sigmoid motility in normal children, children with recurrent abdominal pain and children with ulcerative colitis. Paediatrics 1967;39:539-45.

26. Davidson $\mathrm{M}$, Waserman R. The irritable colon of childhood (chronic nonspecific diarrhea syndrome). J Pediatr 1966;69:1027-38.

27. Read NW, Krejs GJ, Read MG, Santa Ana CA, Morawski SG, Fordtran JS. Chronic diarrhea of unknown origin. Gastroenterology 1980;78:264-71.

28. Milla PJ, Atherton DA, Leonard JV, Wolff OH, Lake BD. Disordered intestinal function in glycogen storage disease. J Inherit Metab Dis $1978 ; 1: 155-7$

29. Tripp JH, Muller DP, Harries JT. Mucosal ( $\mathrm{Na}+-\mathrm{K}+$ )-ATPase and adenylate cyclase activities in children with toddler diarrhea and the postenteritis syndrome. Pediatr Res 1980;14:1382-6.

30. Dodge JA, Hamdi IA, Burns GM, Yamashiro Y. Toddler diarrhoea and prostaglandins. Arch Dis Child 1981;56:705-7.

31. Matuchansky C, Bernier JJ. Effect of prostaglandin E 1 on glucose, water, and electrolyte absorption in the human jejunum. Gastroenterology 1973;64:1111-8.

32. Sandhu BK, Tripp JH, Candy DCA, Harries JT. Loperamide: studies on its mechanism of action. Gut 1981;22:658-62.

33. Savilahti E, Simell O. Chronic non-specific diarrhoea. Arch Dis Child 1985;60:452-6.

34. Corbett CL, Thomas S, Read NW, Hobson N, Bergman I, Holdsworth CD. Electrochemical detector for breath hydrogen determination: measurement of small bowel transit time in normal subjects and patients with the irritable bowel syndrome. Gut 1981;22:836-40.

35. Read NW, Smallwood RH, Levin RJ, Holdsworth CD, Brown BH. Relationship between changes in intraluminal pressure and transmural potential difference in the human and canine jejunum in vivo. Gut 1977;18:141-51.

36. Vantrappen G, Janssens J, Hellemans J, Ghoos Y. The interdigestive motor complex of normal subjects and patients with bacterial overgrowth of the small intestine. J Clin Invest 1977;59:1158-66.

37. Fenton TR, Harries JT, Milla PJ. Disordered small intestinal motility: a rational basis for toddlers' diarrhoea. Gut 1983;24:897-903.

38. Fenton TR, Harries JT, Milla PJ. Abnormalities of postprandial small intestinal motor activity in childhood. Their role in the pathogenesis of the of the irritable bowel syndrome. In: Labo G, Bortolotti M, eds. Gastrointestinal Motility. Verona: Cortina International, 1983:207-13.

39. Diament NF, Hall K, Muir H, El Sharkaway TY. Vagal control of the feeding motor patterns in the lower esophageal sphincter, stomach and upper small intestine of dogs. In: Christensen J, ed. Gastrointestinal Motility. New York: Raven Press, 1980:365-70.

40. Thompson DG, Ritchie HD, Wingate DL. Patterns of small intestinal motility in duodenal ulcer patients before and after vagotomy. Gut 1982;23:517-23.

41. Jonas A, Diver-Haber A. Stool output and composition in the chronic non-specific diarrhoea syndrome. Arch Dis Child 1982;57:35-9.

42. Weaver LT, Steiner H. The bowel habit of young children. Arch Dis Child 1984;59:649-52.

43. Smith VV, Gregson N, Foggensteiner L, Neale G, Milla PJ. Acquired intestinal aganglionosis and circulating autoantibodies without 
neoplasia or other neural involvement. Gastroenterology 1997;112:1366-71.

44. Lake BD, Puri P, Nixon HH, Claireaux AE. Hirschsprung's disease: an appraisal of histochemically demonstrated acetylcholinesterase activity in suction rectal biopsy specimens as an aid to diagnosis. Arch Pathol Lab Med 1978;102:244-7.

45. Aaronson I, Nixon HH. A clinical evaluation of anorectal pressure studies in the diagnosis of Hirschsprung's disease. Gut 1972;13:138-46.

46. Clayden GS, Lawson JO. Investigation and management of long-standing chronic constipation in childhood. Arch Dis Child 1976;51:918-23.

47. Davidson M, Kugler MM, Bauer CH. Diagnosis and management in children with severe and protracted constipated and obstipation. J Pediatr 1963;67:261-75.
48. Bisset WM, Watt JB, Rivers RP, Milla PJ. Ontogeny of fasting small intestinal motor activity in the human infant. Gut 1988;29:483-8.

49. Bisset WM, Watt J, Rivers RP, Milla PJ. Postprandial motor response of the small intestine to enteral feeds in preterm infants. Arch Dis Child 1989;64:1356-61.

50. Thompson DG, Richelson E, Malagelada JR. Perturbation of upper gastrointestinal function by cold stress. Gut 1983;24:277-83.

51. Valori RM, Kumar D, Wingate DL. Effects of different types of stress and of "prokinetic" drugs on the control of the fasting motor complex in humans. Gastroenterology 1986;90:1890-900.

52. Welgan P, Meshkinpour H, Hoehler F. The effect of stress on colon motor and electrical activity in irritable bowel syndrome. Psychosom Med 1985;47:139-49. 


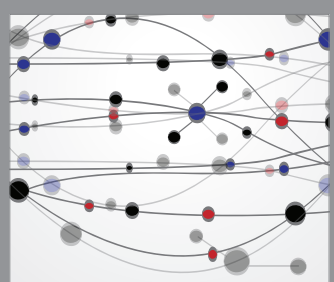

The Scientific World Journal
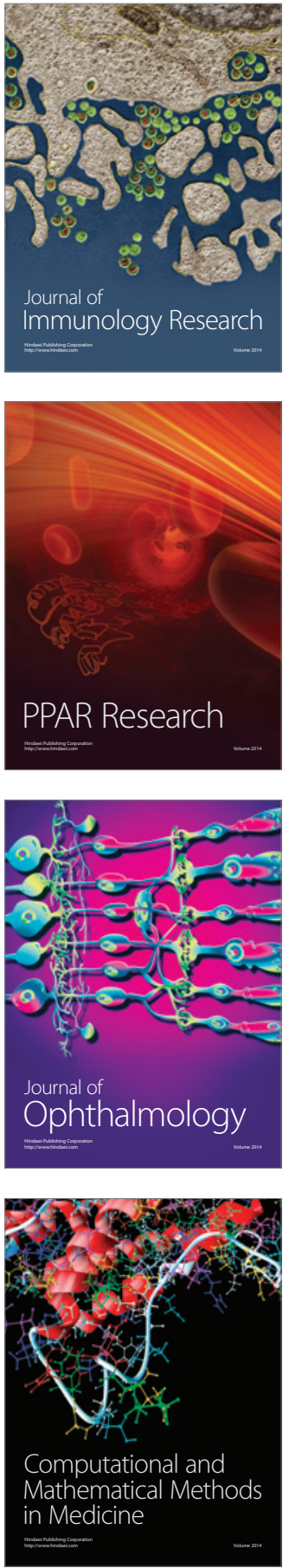

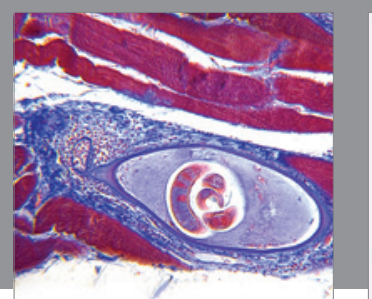

Gastroenterology Research and Practice

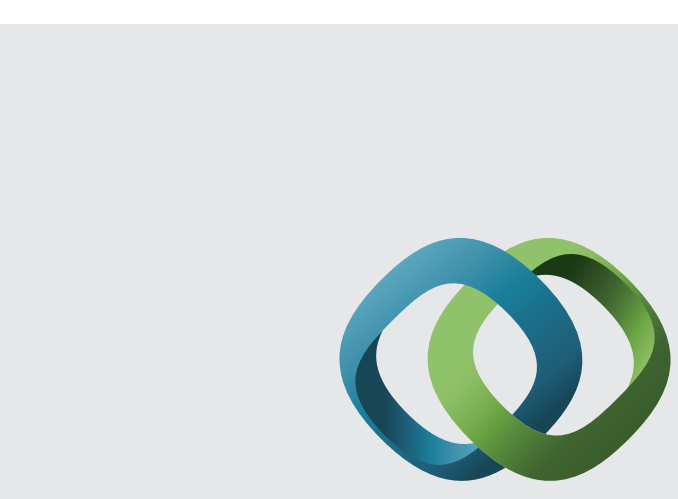

\section{Hindawi}

Submit your manuscripts at

http://www.hindawi.com
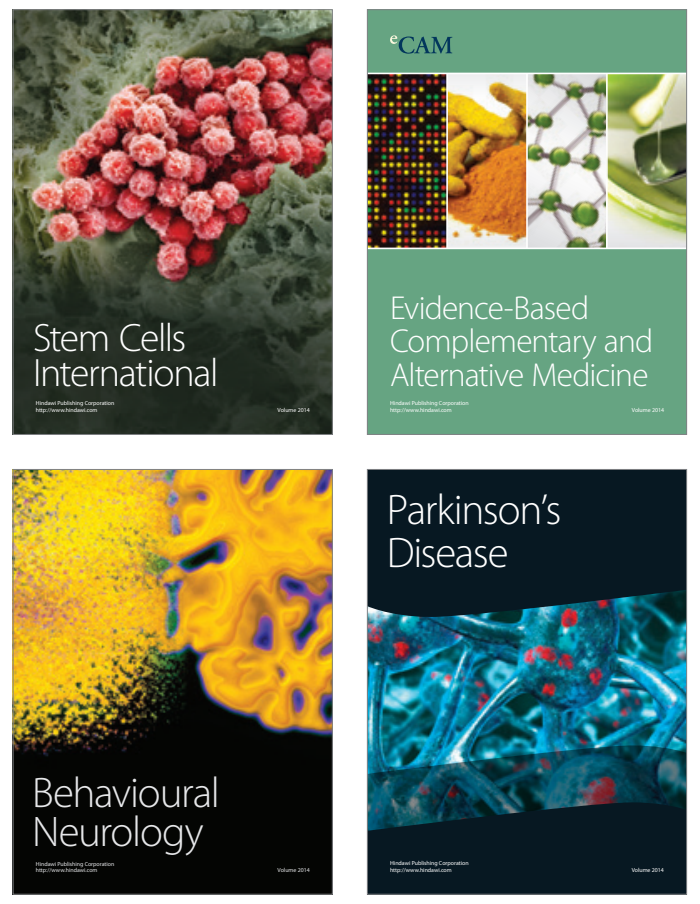
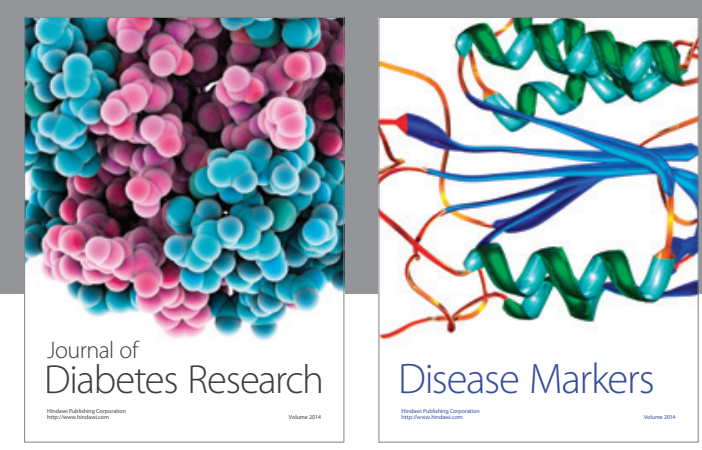

Disease Markers
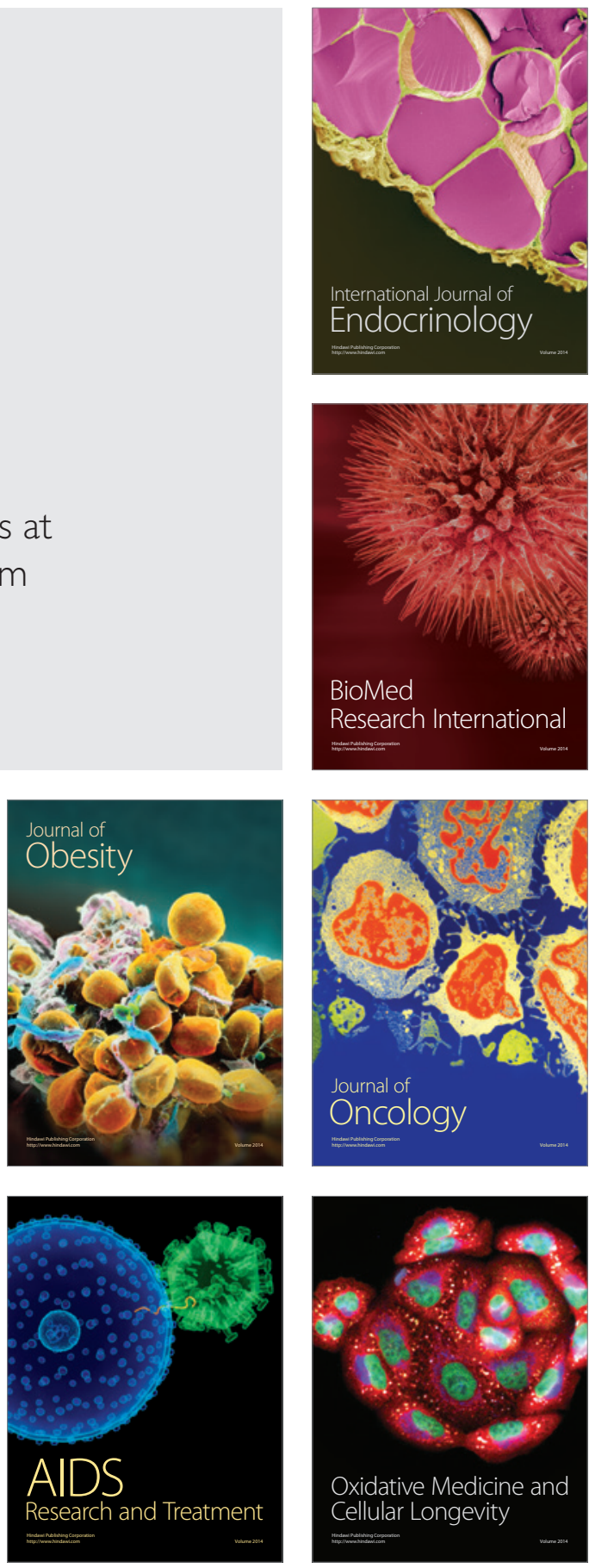